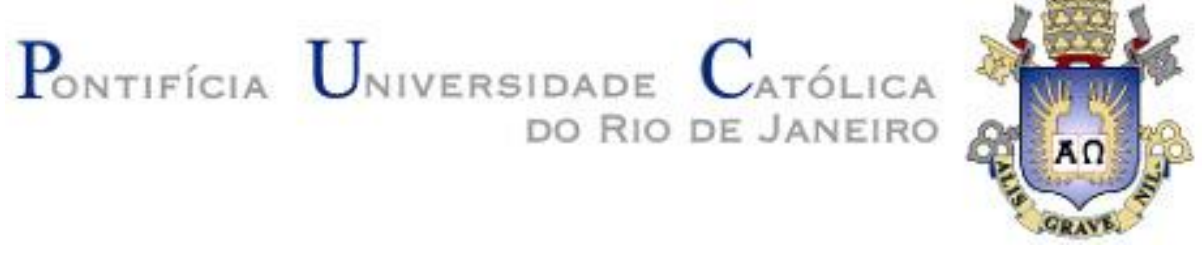

Gabriela Alejandra Huamán Pino

Biossorção de Cádmio por Cocos nucifera: Estudos em Batelada e Contínuo

Tese de Doutorado

Tese apresentada como requisito parcial para obtenção do título de Doutor pelo Programa de Engenharia de Materiais e de Processos Químicos e Metalúrgicos do Departamento Engenharia de Materiais da PUC-Rio.

Orientador: Mauricio Leonardo Torem 


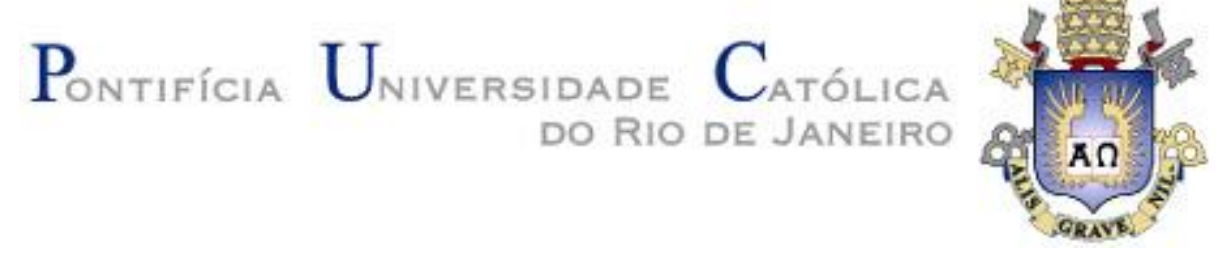

Gabriela Alejandra Huamán Pino

\section{Biossorção de Cádmio por Cocos nucifera: Estudos em \\ Batelada e Contínuo}

Tese apresentada como requisito parcial para obtenção do título de Doutor pelo Programa de Engenharia de Materiais e de Processos Químicos e Metalúrgicos do Departamento Engenharia de Materiais da PUC-Rio. Aprovada pela Comissão Examinadora abaixo assinada.

Dr. Mauricio Leonardo Torem

Orientador

Departamento de Engenharia de Materiais - DEMa - PUC-Rio

Dra. Luciana Maria Souza de Mesquita Agência Nacional de Petróleo - ANP

Dr. Achilles Junqueira Bourdot Dutra PEMM COPPE/UFRJ

Dr. Francisco José Moura

Departamento de Engenharia de Materiais - DEMa - PUC-Rio

Dr. Paulo Sergio Moreira Soares

CETEM

Prof. José Eugenio Leal

Coordenador Setorial de Pós-Graduação do Centro Técnico Científico - PUC-Rio

Rio de Janeiro, 27 de março de 2009 
Todos os direitos reservados. É proibida a reprodução total ou parcial do trabalho sem autorização da universidade, da autora e do orientador.

\section{Gabriela Alejandra Huamán Pino}

Graduou-se em Engenharia Química na Universidad Nacional de San Agustín Arequipa-Perú em 2000, obteve o título de mestre em Engenharia Metalúrgica pela Pontifícia Universidade Católica PUC-Rio em 2005, tendo como área de concentração a metalurgia extrativa.

Ficha Catalográfica

Huamán Pino, Gabriela Alejandra

Biossorção de cádmio por Cocos nucifera : estudos em regime batelada e contínuo / Gabriela Alejandra Huamán Pino ; orientador: Mauricio Leonardo Torem. -2009.

$111 \mathrm{f}$; $30 \mathrm{~cm}$

Tese (Doutorado em Engenharia de Materiais)Pontifícia Universidade Católica do Rio de Janeiro, Rio de Janeiro, 2009.

Inclui bibliografia

1. Engenharia de materiais - Teses. 2. Biossorção. 3. Cádmio. 4. Colunas de leito fixo. 5. Cocos nucifera. I. Torem, Mauricio Leonardo. II. Pontifícia Universidade Católica do Rio de Janeiro. Departamento de Engenharia de Materiais. III. Título. 
Este trabalho afastou-me ainda mais de casa, mas o amor e apoio dos meus pais, Juan Antonio e Carmen, e dos meus irmãos Antonio, Fernanda e Joaquin foi incondicional. As cartas, os telefonemas e os e-mails, trouxeram-me alegria, boas recordações e animo para continuar. Dedico este trabalho a vocês. 


\section{Agradecimentos}

A Deus, pelo que eu sou.

Ao Professor Mauricio Leonardo Torem pela orientação e confiança em mim.

A Embrapa na pessoa do doutor Gustavo Saavedra Pinto, pelo fornecimento da biomassa para a realização desta tese.

Ao departamento de Química da PUC-Rio pela delicadeza de cessão de seus laboratórios, ao professor Reinaldo Calixto de Campos e ao técnico Rodrigo Araújo Gonçalves pela ajuda com as análises de absorção atômica, à professora Maria Isabel Pais da Silva e ao técnico Henrique Meira da Silva pela ajuda com as análises no espectrofotômetro de Infravermelho.

A minha fam ilia, pelo apoio, paciência e compreensão, ao Eduardo sem cujos conselhos e apoio não poderia terminar. Aos meus amigos Osíris e Rosany pela ajuda no tratamento estatístico dos dados experimentais.

Aos meus colegas da PUC-Rio, aos professores, pesquisadores e funcionários do Departamento de Materiais e Metalurgia da PUC-Rio. Às minhas amigas Monica e Belenia pela companhia, conselhos e apoio dado ao longo do trabalho.

Aos meus amigos "da montanha" por momentos inesquecíveis que fizeram desta caminhada mais leve e cuja companhia tornou a distância de casa menos sofrida.

Ao CNPq, CAPES e PUC-Rio pelos recursos e auxílios concedidos. 


\section{Resumo}

Pino, Gabriela Alejandra Huamán; Torem, Mauricio Leonardo; Biossorção de Cádmio por Cocos nucifera: Estudos em Batelada e Contínuo. Rio de Janeiro, 2009. 111 p. Tese de Doutorado - Departamento de Engenharia de Materiais, Pontifícia Universidade Católica do Rio de Janeiro.

O cádmio é um dos maiores agentes contaminantes do meio ambiente devido à sua alta toxicidade, ameaçando às plantas, animais e seres humanos. O uso de biomassas como material sorvente para a remoção do cádmio de efluentes líquidos aparece como uma alternativa promissora às tecnologias existentes. O objetivo desta tese foi determinar a capacidade de adsorção do pó de casca de coco verde (Cocos nucifera) para cádmio num sistema contínuo de biossorção, assim como a dessorção do metal da biomassa, para que esta possa ser utilizada num ciclo de biossorção-dessorção. O equipamento escolhido foi uma coluna de leito fixo. Foram avaliadas a influência da vazão, altura de leito, sentido do fluxo e a eficiência do processo com colunas em série. Os grupos funcionais presentes na superfície da biomassa foram estudados através de análises de espectroscopia no infravermelho. Os experimentos num sistema contínuo com diferentes alturas de leito e concentrações iniciais revelaram que a melhor eficiência do processo foi obtida com maiores alturas de leito $(18 \mathrm{~cm})$ e concentrações iniciais baixas $(19 \mathrm{mg} / \mathrm{l})$. Obtiveram-se tempos de ruptura de 150 minutos para soluções com vazão de $22 \mathrm{ml} / \mathrm{min}$, obtendo-se uma solução com concentração final de 2,6 mg/l. Uma eficiência de remoção de $46 \%$ foi obtida quando se trabalhou com concentrações iniciais de $19 \mathrm{mg} / \mathrm{l}$ e o processo torna-se mais eficiente quando é utilizado um sentido de fluxo ascendente.O EDTA mostrou-se como um excelente eluente ao realizar a dessorção dos íons metálicos contidos na biomassa, num processo em batelada. A biomassa foi submetida a quatro ciclos de biossorção-dessorção, apresentando em cada um deles eficiências de dessorção superiores a 70\% e uma posterior eficiência de remoção superior a $85 \%$ em todos os ciclos. Os grupos funcionais presentes na superfície da biomassa são principalmente 
grupos carboxila, hidroxila, amina e amida. Os resultados apresentados mostram que o pó de casca de coco verde apresenta as características adequadas para o processo de biossorção de cádmio num processo contínuo utilizando colunas de leito fixo, e que pode ser utilizado como uma alternativa aos processos clássicos de tratamento de efluentes.

\section{Palavras-chave}

Biossorção, Cádmio, Colunas de Leito Fixo, Cocos nucifera 


\section{Abstract}

Pino, Gabriela Alejandra Huamán; Torem, Mauricio Leonardo (Advisor). Biosorption of Cadmium by Cocos nucifera: batch and continuous studies. Rio de Janeiro, 2009. 111 p. D.Sc. Thesis - Departamento de Engenharia de Materiais, Pontifícia Universidade Católica do Rio Janeiro.

Cadmium is one of the greatest actors of environmental pollution due to its high toxicity, threatening plants, animals and humans beings. The use of biomass as a sorbent material for cadmium removal seems to be a promising alternative to existing technologies. The objective of this work was to determine the adsorption capacity of coconut shell powder (Cocos nucifera) for cadmium in a continuous system of biosorption, and also the desorption of the metal from the biomass, so that this material could be used in a new cycle of biosorptiondesorption. A fixed bed column was chosen, as it does not present clogging problems and is easy to operate. The influence of flow rate and its direction, bed height and the efficiency of the process with series columns were evaluated. The functional groups present on the surface of the biomass were studied by infrared spectroscopy analysis. The column experiments with different bed heights and initial concentration revealed that the best efficiency was obtained with higher bed heights $(18 \mathrm{~cm})$ and lower initial concentrations $(19 \mathrm{mg} / \mathrm{l})$. Breakthrough time of 150 minutes was obtained for solutions with a flow rate of $22 \mathrm{ml} / \mathrm{min}$, generating a solution with final concentration of $2.6 \mathrm{mg} / \mathrm{l}$. A removal efficiency of $46 \%$ was obtained when working with initial concentrations of $19 \mathrm{mg} / \mathrm{l}$. The process becomes more efficient when the solution is pumped upward through the columnEDTA was an excellent elutant for desorption of metal ions in the biomass in a batch system. The biomass was subjected to four biosorption-desorption cycles, presenting higher than $70 \%$ desorption efficiencies and removal efficiencies of more than $85 \%$ in all cases. The functional groups presents on the particle surface of the biomass are mainly carboxyl, hydroxyl, amine and amide groups. The results show that the powder of coconut shell has the appropriate 
characteristics for biosorption of cadmium in a continuous process using columns of fixed bed, which can be used as an alternative to conventional processes for effluent decontamination.

\section{Keywords}

Biosorption, Cadmium, Fixed Bed Columns, Cocos nucifera 


\section{Sumário}

1 INTRODUÇÃO 14

1.1. Objetivos e Relevância do Trabalho 16

2 REVISÃO BIBLIOGRÁFICA 18

2.1. Cádmio 18

2.2. Métodos Convencionais de Remoção de Metais Pesados 23

2.3. Biossorção $\quad 25$

2.3.1. Sistemas Contínuos no Processo de Biossorção 29

2.3.1.1. Colunas de Leito Fluidizado 30

2.3.1.2. Colunas de Leito Fixo 31

2.3.1.3. Colunas de Leito Expandido 32

2.3.1.4. Bioflotação 33

2.3.2. Variáveis Envolvidas no Processo de Biossorção 33

2.4. Biomassa 36

2.5. Biomassas Utilizadas na Biossorção de Cádmio 40

2.6. Cocos nucifera 41

2.7. Adsorção 46

2.7.1. Tipos de Adsorção 46

2.7.2. Curvas de Ruptura $\quad 47$

2.8. Dessorção $\quad 50$

3 MATERIAIS E MÉTODOS

3.1. Material Biossorvente $\quad 53$

3.2. Soluções $\quad 54$

3.2.1. Solução de Cádmio 54

3.2.2. Soluções para o Ajuste do pH 55

3.2.3. Soluções para o Processo de Dessorção 55

3.3. Experimentos de Biossorção em Sistema Contínuo 55

3.3.1. Experimentos com Variação de Vazão $\quad 57$

3.3.2. Experimentos com Variação de Altura do Leito 58

3.3.3. Experimentos com Variação do Sentido do Fluxo 58

3.3.4. Experimentos com Colunas em Série $\quad 58$ 
3.3.5. Experimentos com Variação da Concentração Inicial 58

3.4. Experimentos de Dessorção 59

3.5. Determinações Analíticas $\quad 60$

3.5.1. Determinação da Concentração do Cádmio por Espectrofotometria de $\begin{array}{ll}\text { Absorção Atômica } & 60\end{array}$

3.5.2. Determinação dos Grupos Funcionais por Espectroscopia no Infravermelho

60

4 RESULTADOS E DISCUSSÃO 62

4.1. Caracterização da Biomassa 62

4.2. Ensaios de Biossorção 66

4.2.1. Efeito da Variação da Vazão 68

4.2.2. Efeito da Variação da Altura do Leito 70

4.2.3. Efeito do Sentido do Fluxo 72

4.2.4. Colunas de Leito Fixo em Série $\quad 74$

4.2.5. Efeito da Variação da Concentração Inicial 77

4.2.6. Curvas de Ruptura $\quad 80$

4.3. Ensaios de Dessorção $\quad 85$

5 CONCLUSÕES 93

6 RECOMENDAÇÕES 95

7 REFERÊNCIAS BIBLIOGRÁFICAS 96

8 ANEXOS 106

8.1. Resolução CONAMA $397 \quad 106$

8.2. Determinação do Potencial Zeta 109

$\begin{array}{ll}\text { 8.3. Efeito do } \mathrm{pH} & 110\end{array}$ 


\section{Lista de figuras}

Figura 1 Fontes de poluição de cádmio 19

Figura 2 - Mecanismo de Biossorção 26

Figura 3 - Partes do coco verde. $\quad 45$

Figura 4 - Curva de ruptura típica para processo em coluna de leito fixo $\quad 49$

Figura 5 - Curvas de ruptura para (a) ZTM estreita e (b) ZTM mais ampla 50

Figura 6 - Fluxograma das etapas de obtenção do pó de casca de coco 53

Figura 7 - Pó de casca de coco verde $\quad 54$

Figura 8 - Desenho e fotografia da coluna de biossorção 56

Figura 9 - Desenho da linha experimental do sistema contínuo de biossorção 57

Figura 10 - Microfotografias da partícula de pó de casca de coco 63

Figura 11 - EDS da partícula de casca de coco 64

Figura 12 - Espectro de Infravermelho do pó de casca de coco natural. $\quad 64$

Figura 13 - Microfotografias de partículas carregadas com íons Cd (II) 66

Figura 14 - EDS da partícula carregada com íons de cádmio 67

Figura 15 - Espectro de infravermelho da biomassa carregada 68

Figura 16 - Efeito da variação da vazão $\quad 69$

Figura 17 - Efeito da variação d altura do leito $\quad 71$

Figura 18 - Efeito da variação do sentido do fluxo 73

Figura 19 - Sistema de colunas em série $\quad 75$

Figura 20 - Curvas de ruptura num sistema em série $\quad 76$

Figura 21 - Efeito da concentração inicial 78

Figura 22 - Dessorção de cádmio com diferentes eluentes. 86

Figura 23 - Dessorção de cádmio 88

Figura 24 - Percentagem de remoção de cádmio pela biomassa regenerada 89

Figura 25 - Espectro de infravermelho do pó de casca de coco antes e após o processo de dessorção utilizando EDTA 90

Figura 26 - Espectro de infravermelho do pó de casca de coco antes e após o processo de dessorção utilizando $\mathrm{HCl}$ 0,1 M. 91

Figura 27 - Medição do potencial zeta do pó da casca de coco 109

Figura 28 - Efeito do $\mathrm{pH} \quad 111$

Figura 29 - Diagrama especiação do cádmio 111 


\section{Lista de tabelas}

Tabela 1 - Limites máximos permissíveis para efluentes contendo metais pesados

Tabela 2 - Vantagens e desvantagens dos métodos convencionais para a remoção de metais pesados $\quad 25$

Tabela 3 - Comparação entre colunas de leito fixo e de leito fluidizado. 32

Tabela 4 - Classificação de resíduos que podem ser utilizados como biossorventes

Tabela 5 - Vantagens e desvantagens da utilização de biomassas ativas ou inativas.

Tabela 6 - Principais grupos funcionais presentes nas biomassas susceptíveis de participar na união a metais pesados

Tabela 7 - Caracterização química típica da casca de coco verde

Tabela 8 - Composição química da casca de coco e da fibra de coco.

Tabela 9 - Comparação entre adsorção física e química.

Tabela 10 - Distribuição granulométrica do pó de casca de coco verde. 62

Tabela 11 - Faixas de absorção no infravermelho e grupos funcionais 65

Tabela 12 - Biossorção de cádmio em coluna de leito fixo a diferentes vazões 69

Tabela 13 - Biossorção de cádmio em coluna de leito fixo a diferentes alturas de leito

Tabela 14 - Biossorção de cádmio em coluna de leito fixo com sentidos de fluxo diferentes

Tabela 15 - Biossorção de cádmio em sistema de colunas em série 76

Tabela 16 - Efeito da concentração inicial no processo de biossorção

Tabela 17 - Parâmetros do processo de biossorção de cádmio em processo contínuo

Tabela 18 - Dessorção de cádmio utilizando diferentes eluentes 